\title{
Article
}

\section{White Grape Pomace Valorization for Remediating Purposes}

\author{
Simona Gavrilaș (D), Ioan Calinovici, Sabin Chiș, Claudiu-Ștefan Ursachi, Mirabela Raț \\ and Florentina-Daniela Munteanu *(D)
}

check for updates

Citation: Gavrilaș, S.; Calinovici, I.; Chiș, S.; Ursachi, C.-Ș.; Raț, M.; Munteanu, F.-D. White Grape

Pomace Valorization for Remediating Purposes. Appl. Sci. 2022, 12, 1997. https://doi.org/10.3390/ app12041997

Academic Editor: Ioanna Vasiliadou

Received: 20 January 2022

Accepted: 11 February 2022

Published: 14 February 2022

Publisher's Note: MDPI stays neutral with regard to jurisdictional claims in published maps and institutional affiliations.

Copyright: (c) 2022 by the authors. Licensee MDPI, Basel, Switzerland. This article is an open access article distributed under the terms and conditions of the Creative Commons Attribution (CC BY) license (https:// creativecommons.org/licenses/by/ $4.0 /)$.
Faculty of Food Engineering, Tourism and Environmental Protection, "Aurel Vlaicu" University of Arad, 2-4 E. Drăgoi Str., 310330 Arad, Romania; simona.gavrilas@uav.ro (S.G.); ioan.calinovici@uav.ro (I.C.); sabin.chis@uav.ro (S.C.); claudiu.ursachi@uav.ro (C.-S.U.); mirabela_28@yahoo.com (M.R.)

* Correspondence: florentina.munteanu@uav.ro

Featured Application: A potential application of the proposed topic considers the opportunity of agro-industrial waste valorization to reduce its environmental impact. The designed approach opens the possibility of improving specific indicators of the wastewaters from hemp-retting processing.

\begin{abstract}
The present investigation focuses on a possible alternative to reduce grape pomace's negative impact on the environment by exploiting its capacities for wastewater remediation. Therefore, three directions are followed: (1) the characterization of white grape byproducts' antioxidant and antiradical properties; (2) the determination of organophosphorus compound concentration that might be present in the samples; and (3) the evaluation of the possible use for wastewater remediation. The grape pomace was used for obtaining different extracts considering different extraction conditions. The hydroalcoholic extracts have an increased amount of total phenolic content. The lyophilized hydroalcoholic extract showed high total phenolic content (159.52 mg/100 g) and low organophosphorus content $(0.257 \pm 0.015 \mathrm{nmol})$. The lowest DPPH antiradical-scavenging activities were obtained for the extracts in ethanol obtained from refrigerated pomace $(0.055)$ and for dried pomace (0.045).
\end{abstract}

Keywords: agro-waste valorization; organophosphorus compounds; wastewater characteristics

\section{Introduction}

The applicability of the circular economy concept is gradually increasing. More and more byproducts are used in new and different processes [1-9]. Agro-industrial wastes, for example, have important applications in bioremediation. Adsorbents obtained based on waste from tea leaves proved their efficiency in chelation chromium (VI) from polluted water [10]. Different nanoparticles, synthesized based on agro-wastes, have shown possibilities for use in wastewater remediation. The palladium nanostructures might remove toxic azo dyes from water and wastewaters [11]. The same concept was tested in other research for antibiotic removal [12]. Another direction linking agro-waste and possible wastewater toxics removal is the nanocomposites [13-15].

The present investigation examines current trends of agriculture waste valorization for wastewater remediation. In our opinion, the chosen subject is one of interest, knowing that the textile industry is an important water consumer and, at the same time, a polluter.

The grape chemical composition depends on the annual climate conditions and soil pedology. All the solid mass resulting from grape processing might represent an environmental problem because of the contribution to the carbon footprint. Therefore, it is necessary to implement sustainable exploitation measures in the case of grape pomace.

Winery waste represents an essential source of soluble and insoluble fibers and complex and straightforward polyhydroxy phenols, proteins, and oils [16-20]. These products are successfully used in foods, cosmetics, drugs, or animal feed components to improve the products' physicochemical properties [21-28]. The antioxidant and antimicrobial activity 
presented by the grape pomace is related to its polyhydroxy phenol composition [29]. The pomace fibers and phytochemicals, if included in the diet, have the health benefit of preventing different diseases [19,30-34].

The winery byproducts' chemical compositions can be valorized in multiple directions. One refers to the extraction of valuable nutrients, the other to the possibility of using them as biosorbents for the removal of different contaminants [35] or as a source for molecules biosynthesis. They can be included in biochemical processes as useful sources of nutritive elements [36]. Their fermentation with different microorganisms results in a significant quantity of enzymes. These can be further purified and valorized. Their second property refers to the capacity of promoting the hydrolysis of the pomace cellular walls for a more accessible release of the nutrients [37], as well as for obtaining eutectic solvents [38] or using as a source of natural antibiotics for the poultry industry [39]. The considered methods have the primary objective of developing sustainable analytic methods and reducing the impact on the ecosystems throughout the circular economy concept. The wine byproducts can be further valorized for extraction of bioactive compounds or biosorbents, as previously reported by Diaz-Ramirez et al. [40].

A new promising application, reported by Diaz et al., uses a mix of grape pomace and orange peels as sources of exopolygalacturonase and xylanase, enzymatic products with applications in wine and juice production [41]. The chemical composition of grape pomace influences its further utilization. Its content in cellulose and lignocellulose determines the amount of biomethane resulting from anaerobic digestion [42]. Thermally treated pomace grape form a porous selective surface. By electrostatic absorption, divalent heavy metals, such as $\mathrm{Ni}, \mathrm{Zn}, \mathrm{Pb}$, and $\mathrm{Cd}$, can be bound to this porous surface, transforming the winery waste into a bioremediation tool [43].

The data presented in the literature underline the importance of different pretreatments made on grape pomace. The pomace's hydrothermal and enzymatic properties are synergetic [44]. The hydrolysis of the pectic substances increases the accessibility to various essential biomolecules of the byproduct. Moreover, the extraction media influence the type of the extracted polyhydroxy phenol [45] and the methanol production [46].

Recent studies evaluated the capacity of pomace's antiseptic properties, which were explored in the form of silver nanoparticles [47].

This paper aims to characterize the white grape as a source of antioxidants and antiradicals. The organophosphorus content was also determined, as it represents a potentially toxic impact on the human body and the environment. In addition, the possible reintegration of this waste in nature, such as compost, can increase the content of toxic compounds in the soil, groundwater, plants grown in that area, or the body of animals fed with contaminated feed.

The investigation's novelty is reflected by the variety of the formulated extraction systems. These were used for the treatment of wastewaters from the hemp-retting processes. The intention is to improve the qualitative wastewater parameters before discharge using ecological mechanisms. Another aspect that needs to be underlined refers to the analytic approaches. The enzymatic methods were used for the sample's antiradical characterization and pesticide quantification. A practical application for extracts was also designed. The use of pomace and its valorization for wastewater remediation was previously reported in the literature [47]. In the present study, we emphasize that the extracts obtained from pomace can depollute the waters resulting from hemp fiber retting. Such an approach arose from the desire to develop bidimensional ecological tools. The conceived scenario follows a green integrated attitude of decreasing solid winery waste through wastewater quality improvement and possibly enriching the soil based on its use. 


\section{Materials and Methods}

\subsection{Sample Preparation}

White grape pomace was provided by ICDVV Valea Călugărească, Romania. Samples were refrigerated $\left(4^{\circ} \mathrm{C}\right)$ until the pretreatments were applied. It was not fermented, and it consisted of grape peels, seeds, and pulp.

The used wastewaters were obtained from the in-house experimental processes of hemp retting.

The grape pomace pretreatments are summarized in Table 1.

Table 1. Grape pomace thermal treatments.

\begin{tabular}{|c|c|c|}
\hline Abbreviation & Extractive Media & Pomace Treatment \\
\hline \multicolumn{3}{|c|}{ Extraction } \\
\hline PRE 1 & hydroalcohol & refrigeration \\
\hline PRE 2 & water & refrigeration \\
\hline PDE 1 & hydroalcohol & drying \\
\hline PDE 2 & water & drying \\
\hline PLE 1 & hydroalcohol & lyophilization \\
\hline PLE 2 & water & lyophilization \\
\hline \multicolumn{3}{|c|}{ Ultrasound Macerates } \\
\hline PLU 1 & hydroalcohol & lyophilization \\
\hline PLU 2 & water & lyophilization \\
\hline \multicolumn{3}{|c|}{ Stirred Macerates } \\
\hline PLS 1 & hydroalcohol & lyophilized \\
\hline PLS 2 & water & lyophilized \\
\hline
\end{tabular}

\subsection{Reagents}

All the reagents used were purchased from Sigma-Aldrich (Sigma-Aldrich, St. Louis, MO, USA) and have a purity $\geq 98 \%$.

\subsection{Polyhydroxy Phenol Compound Extraction}

Before extraction, the grape pomace was treated at different temperatures. The first approach consisted of drying at $30{ }^{\circ} \mathrm{C}$ in a thermostatic atmosphere until constant mass (D) using a Binder classic heater with forced convection. The second approach (L) was performed in a lyophilizer, Martin Christ, Alpha 1-2. The instrument has a two-stage refrigeration system, which was used until samples reached temperatures of $-55^{\circ} \mathrm{C}$ and $-85^{\circ} \mathrm{C}$. In the third situation, the samples were only refrigerated at $4{ }^{\circ} \mathrm{C}(\mathbf{R})$. All samples were finely grounded in a coffee grinder that is used specifically for these experiments. The coffee grinder (Zass, ZCG 03) has a power of $200 \mathrm{~W}$ and a maximum load capacity of $90 \mathrm{~g}$. The milling process was made in three steps of $3 \mathrm{~min}$ each, with a 1-min pause between each step.

The grape pomace was macerated for $24 \mathrm{~h}$ at room temperature and stirred (S) at $750 \mathrm{rpm}$, or treated by ultrasound (U) $(35 \mathrm{kHz})$ for $2.5 \mathrm{~h}$. An extraction was also performed using the Soxhlet system (E) for $2.5 \mathrm{~h}$. The extraction media, $100 \mathrm{~mL}$, consisted of distilled water (2) or an ethanol/water solution with a 1:1 ratio (1) in which $10 \mathrm{~g}$ of the sample were immersed. The extracts were centrifuged at 15,000 rpm for $10 \mathrm{~min}$, in a Rotina 360R system. With a rotary evaporator IKA RV10, the supernatant was evaporated to $100 \%$ and freeze dried. All determinations were made in triplicates.

\subsection{Total Phenol Content Determination}

The total phenol content (TPC) was determined using Folin-Ciocalteau reagent (FCR) slightly modified for micro samples. The extinction measurement was made at $750 \mathrm{~nm}$ using a Thermo Multiscan Ex spectrophotometer (Electron Corporation). The reaction mixture contained $125 \mu \mathrm{L}$ FCR and $25 \mu \mathrm{L}$ of the sample. The mixture was incubated 
for $8 \mathrm{~min}$ at $37^{\circ} \mathrm{C}$, agitated at $400 \mathrm{rpm}$ in a heated microplate vortex (INCU-Mixer MP, Benchmark), added to $100 \mu \mathrm{L}$ of $7.8 \% \mathrm{Na}_{2} \mathrm{CO}_{3}$, and incubated for $1 \mathrm{~h}$. The results are expressed as gallic acid mg equivalents.

\subsection{Antioxidant and Antiradical Activity}

\subsubsection{DPPH Method}

The antioxidant capacity using the DPPH reagent was expressed as Trolox mg equivalents. The samples were diluted in ethanol, and the absorbance was measured at $490 \mathrm{~nm}$. The method was adapted for microplate determinations. A mixture of $200 \mu \mathrm{L}$ ethanol, $25 \mu \mathrm{L}$ sample, and $25 \mu \mathrm{L}$ of DPPH was incubated for $20 \mathrm{~min}$ at $400 \mathrm{rpm}$ at $25^{\circ} \mathrm{C}$ and then measured against a blank solution.

\subsubsection{ABTS Method}

An aliquot of $25 \mu \mathrm{L}$ sample and $225 \mu \mathrm{L}$ ABTS were incubated for $3 \mathrm{~min}$ at $25^{\circ} \mathrm{C}$ and $400 \mathrm{rpm}$, and the absorbance was measured at $405 \mathrm{~nm}$. The results of the ABTS radical reduction are expressed as gallic acid mg equivalents.

\subsubsection{NBT Method}

The method has an enzymatic profile and is based on the in vitro production of oxygen radicals and uric acid. The compounds are the results of the hypoxanthine/xanthine oxidase (HX/XOD) system. The oxygen radicals reduce the NBT reagent and form formazan (purple colored) [48,49]. The absorbance was measured at $560 \mathrm{~nm}$, and the results are expressed as gallic acid mg equivalents. Good results are obtained for the samples diluted in K-PBS $50 \mathrm{mM}$ in the presence of EDTA $0.1 \mathrm{mM}$ buffer, $\mathrm{pH}$ 7.5. For the measurements we used $150 \mu \mathrm{L}$ K-PBS, $25 \mu \mathrm{L} \mathrm{HX}, 25 \mu \mathrm{L}$ sample, and $25 \mu \mathrm{L}$ NBT (nitrotetrazolium blue chloride) that were incubated at $25^{\circ} \mathrm{C}$ for $5 \mathrm{~min}$ and $700 \mathrm{rpm}$, then $25 \mu \mathrm{L}$ XOD was added, followed by incubation at $25^{\circ} \mathrm{C}$ for $15 \mathrm{~min}$ and at $700 \mathrm{rpm}$.

\subsection{Amperometric Detection of Organophosphorus Compounds}

For the amperometric detection of the organophosphorus content, a screen-printed electrode with a three-electrode configuration was used, as previously reported by Andreescu et al. [50].

The electrode was immersed in a reaction cell containing $5 \mathrm{~mL}$ of $0.1 \mathrm{M}$ phosphate buffer at $\mathrm{pH}=7$, connected to a potentiostat. It was applied to a potential of $+100 \mathrm{mV}$ between the reference electrode and the working electrode. This potential allows the oxidation of cobalt phthalocyanine mediator (CoPC) incorporated in the working electrode. For the electrochemical experiments, Nova 2.1.3 software was used. The immobilized enzyme activity and the inhibition degree were performed by amperometric measurements in agitated solution and expressed in nmol chlorpyrifos-oxone equivalent and inhibition percentage. All determinations were performed using $0.1 \mathrm{M}$ phosphate buffer, $\mathrm{pH}=7$.

\subsection{Wastewater Parameters Analysis}

The investigations were made on wastewater resulting from hemp treatment. The considered parameters were the $\mathrm{pH}$, conductivity, total dissolved oxygen, and turbidity. The measurement instruments were the WTW multi-parameter inoLab Multi 740 and the Turbidimeter HI 88713 from HANNA Instruments.

The alcoholic extracts were used in the ratio of 1:10 ( $V: V$, extract:hemp wastewater). For these experiments, $1 \mathrm{~mL}$ of pomace extract was added to $10 \mathrm{~mL}$ of wastewater. The freshly prepared mixtures were stirred for $1 \mathrm{~min}$ at $750 \mathrm{rpm}$ and kept at room temperature during the analysis period. Triplicate determinations were made. 


\section{Results}

\subsection{Total Phenol Content}

The total phenol content was evaluated for all the obtained extracts. The highest content of phenolic compounds is observed for the sample obtained through the extraction in ethanol independent of the used treatment (Figure 1). The findings follow the results published by López-Miranda et al. who showed that the mixture of ethanol and water contributed to the highest content of phenolic compound [51]. Moreover, our reported TPC values for the extraction in ethanol/water under stirring are similar to their reported values.

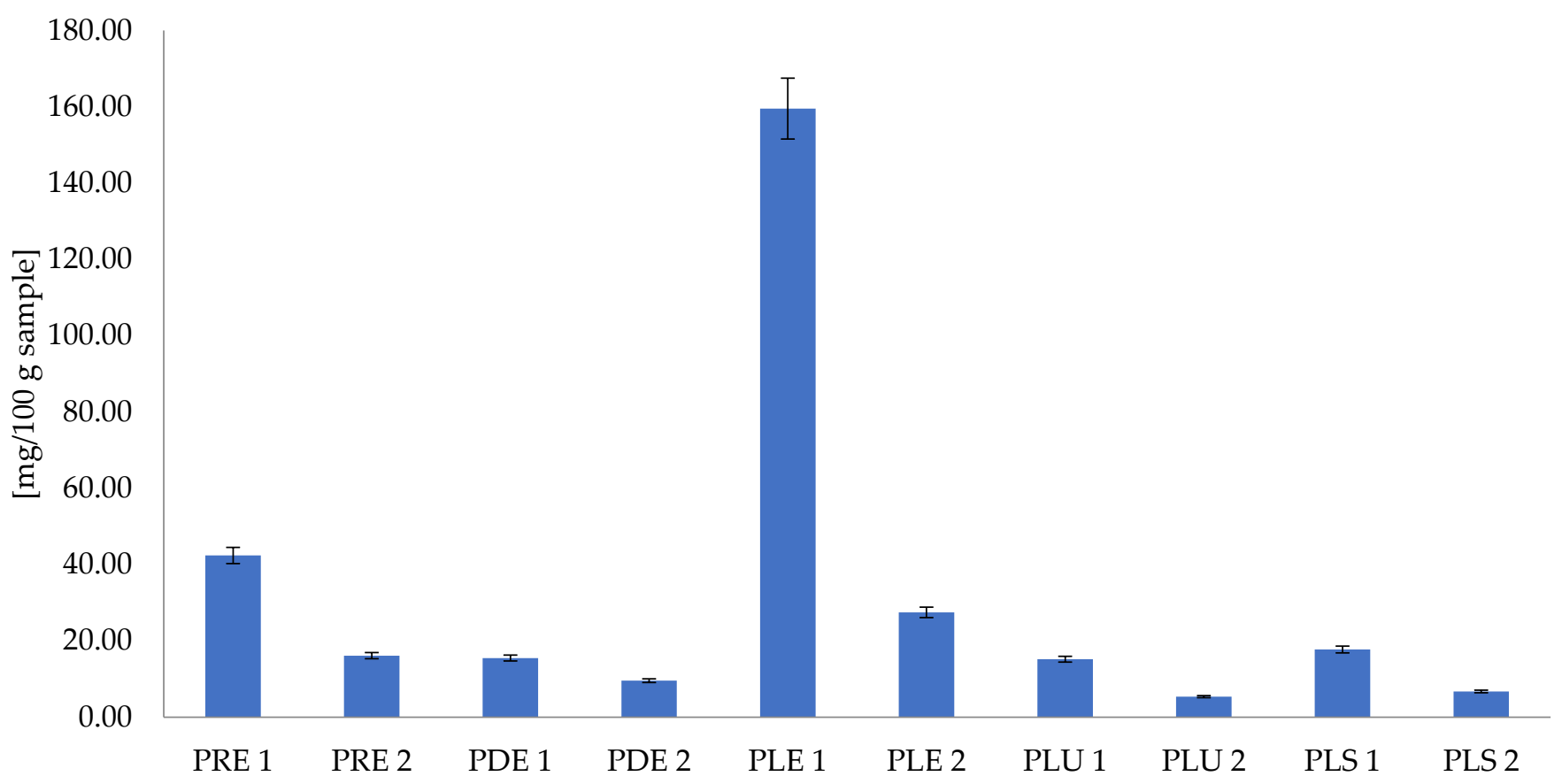

Figure 1. Total phenol content.

Another positive effect in the case of the extracted samples is brought by the lyophilization treatment that can be considered to contribute to phenol content preservation. The results indicate that in the lyophilized samples, the value obtained for the phenol content is almost four times higher than the level registered for the refrigerated samples (159.52 mg/100 g sample for LE 1 compared to $42.39 \mathrm{mg} / 100 \mathrm{~g}$ sample for RE 1). The results are in accordance with the data presented in the literature regarding the positive influence of lyophilization on grape waste treatments [52]. It should also be pointed out that the ultrasound treatment does not significantly influence the results obtained, and we assume that the time for the ultrasonication was too high, and therefore, the extraction yield was lower.

\subsection{Antioxidant and Antiradical Activity}

Figures 2 and 3 show that all samples have antiradical activity independent of the pretreatment applied. The effect is present even at the lowest aqueous extract concentration. In the case of these samples, the process seems to be influenced by the temperatures used at the minimum concentration in the experiments; only the refrigerated samples present antiradical activity. 


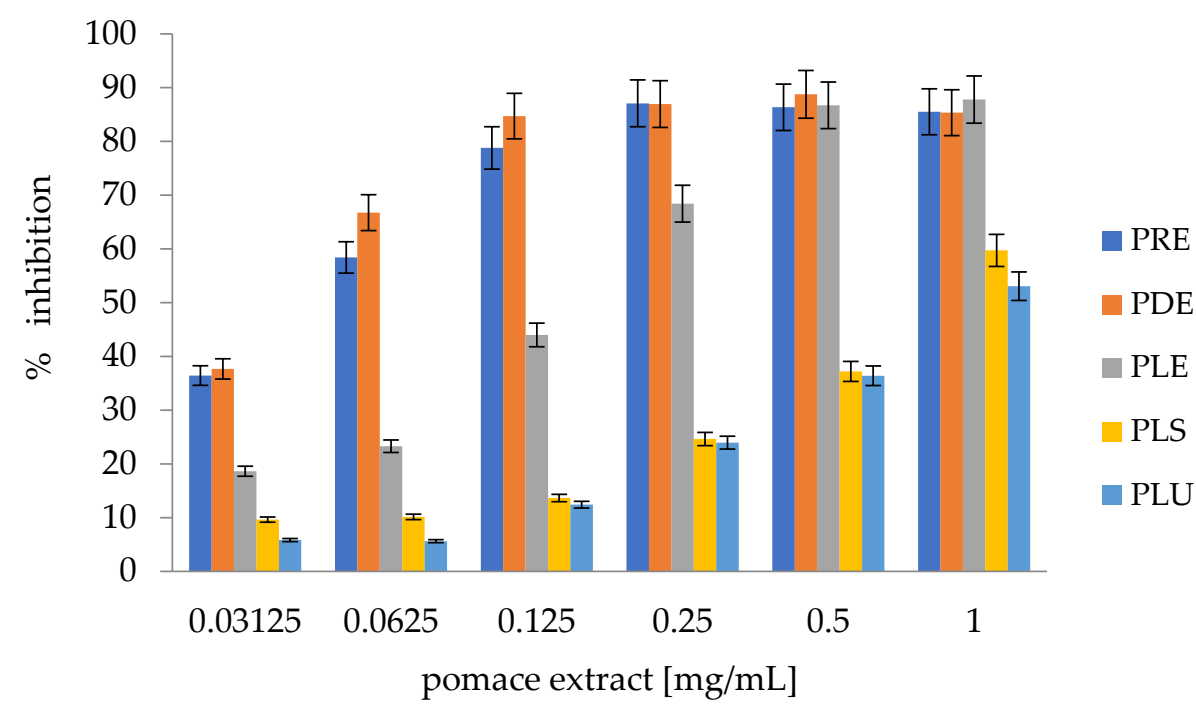

Figure 2. $\mathrm{DPPH}^{\bullet}$ scavenging activity at different pomace concentrations in ethanol-water. PRE-hydroalcoholic extract of refrigerated pomace; PDE-hydroalcoholic extract of dry pomace; PLE-hydroalcoholic extract of lyophilized pomace; PLU-hydroalcoholic ultrasound macerate of lyophilized pomace; PLS-hydroalcoholic stirred macerate of lyophilized pomace.

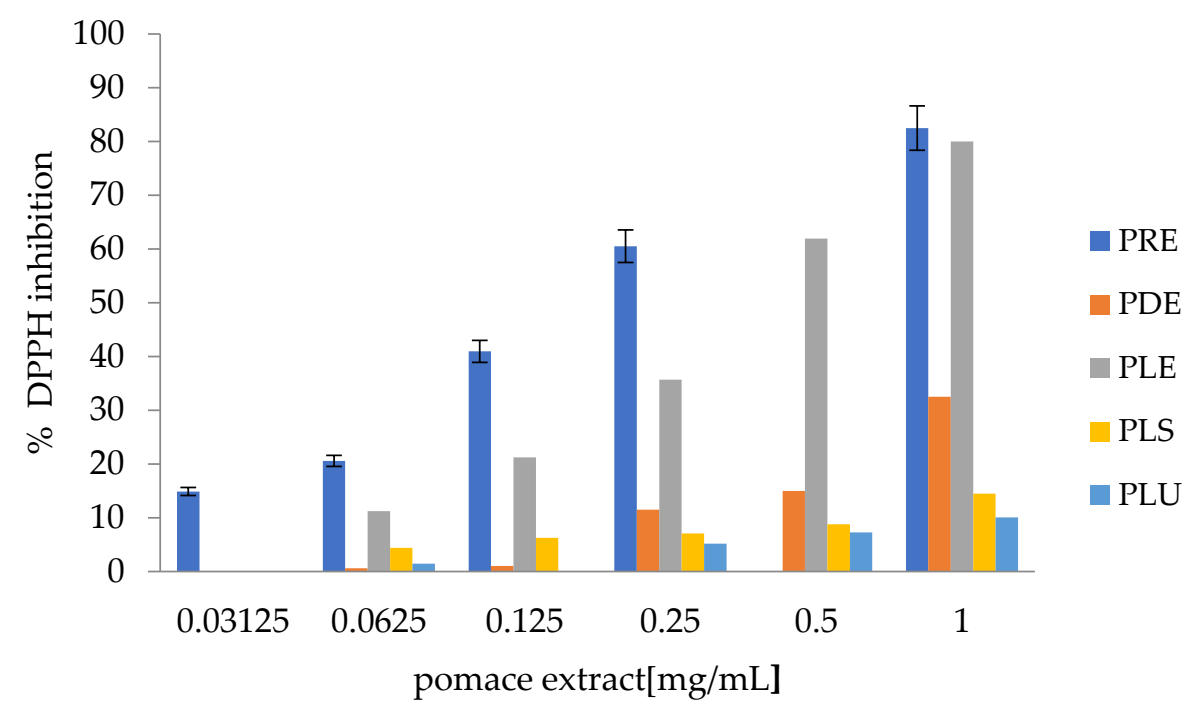

Figure 3. $\mathrm{DPPH}^{\bullet}$ scavenging activity at different pomace concentrations in water. PRE-aqueous extract of refrigerated pomace; PDE-aqueous extract of dry pomace; PLE-aqueous extract of lyophilized pomace; PLU-aqueous ultrasound macerate of lyophilized pomace; PLS-aqueous-stirred macerate of lyophilized pomace.

For the evaluation of the antioxidant activity, we used the IC 50 parameter, which refers to the necessary concentration of antioxidant that reduces the DPPH concentration by $50 \%$. A low value for IC 50 corresponds with a higher antioxidant capacity.

According to the data presented in Table 2, the most efficient extraction, in terms of half of the maximum inhibitory concentration, was obtained in the case of dried samples in alcoholic media. It can be observed that despite the highest content of phenolic compounds in the lyophilized extracts, the IC 50 does not reveal the same. This behavior might be due to the presence of phenolic compounds with weak radical-scavenging activity in the lyophilized extracts, but further studies are necessary to prove this assumption. 
Table 2. IC $50{ }^{1}$ values for $\mathrm{DPPH}{ }^{\bullet}$ scavenging activity.

\begin{tabular}{ccc}
\hline Sample, $[\mathrm{mg} / \mathrm{mL}]$ & Ethanol-Water & Water \\
\hline PRE & 0.055 & 0.192 \\
PDE & 0.045 & 1.545 \\
PLE & 0.166 & 0.388 \\
PLS & 0.785 & 4.395 \\
PLU & 0.709 & 7.238 \\
\hline
\end{tabular}

${ }^{1}$ IC 50: Half of the maximum inhibitory concentration.

As shown in Figures 4 and 5, the water-obtained extracts exhibit lower activity in ABTS-scavenged radicals than the extracts obtained in the mixture of ethanol and water. For the hydroalcoholic extracts, in the case of ABTS-scavenging activity, it is necessary to have a higher concentration of the extracts than that exhibited for the DPPH radicals.

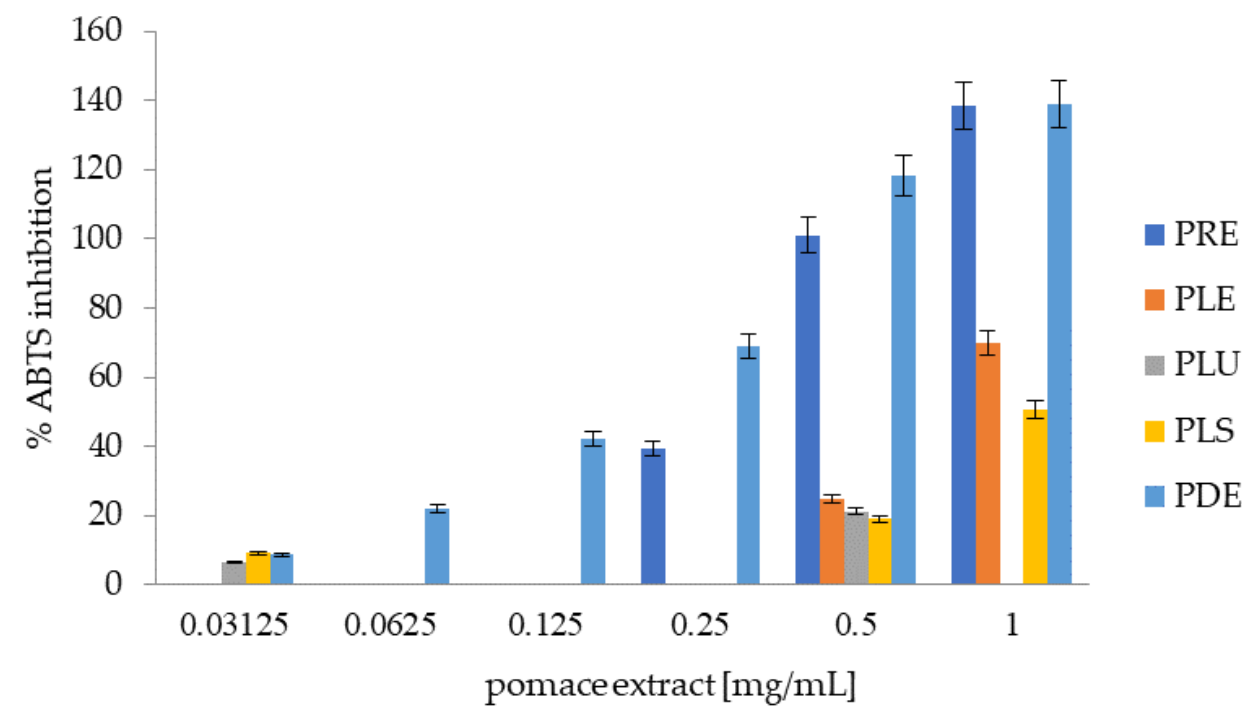

Figure 4. $\mathrm{ABTS}^{\bullet+}$ scavenging activity at different pomace concentrations in ethanol-water. PRE-hydroalcoholic extract of refrigerated pomace; PDE-hydroalcoholic extract of dry pomace; PLE-hydroalcoholic extract of lyophilized pomace; PLU-hydroalcoholic ultrasound macerate of lyophilized pomace; PLS-hydroalcoholic stirred macerate of lyophilized pomace.

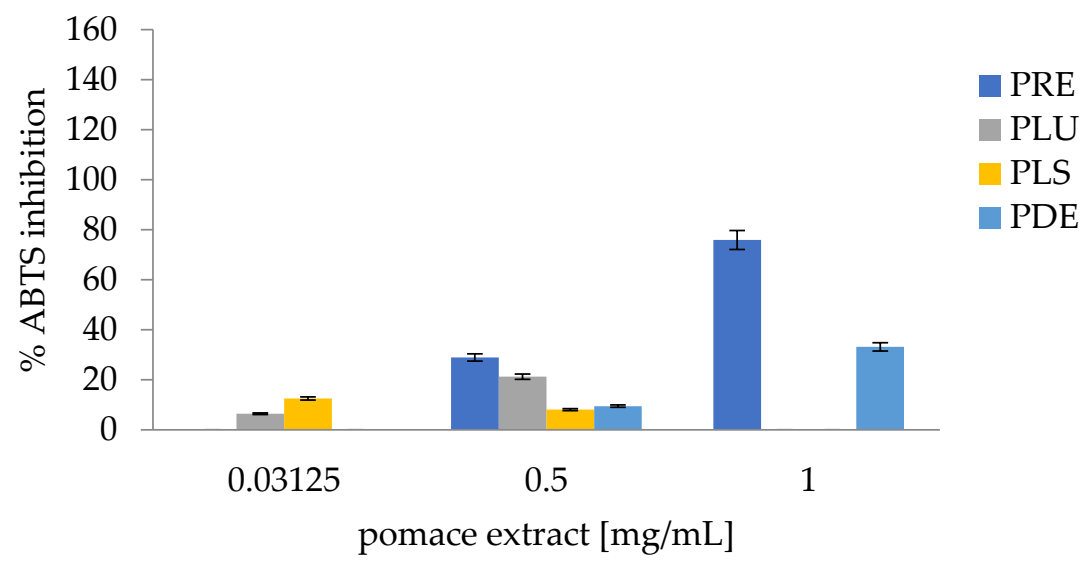

Figure 5. $\mathrm{ABTS}^{\bullet+}$ scavenging activity at different pomace concentrations in water. PRE-aqueous extract of refrigerated pomace; PDE-aqueous extract of dry pomace; PLU-aqueous ultrasound macerate of lyophilized pomace; PLS-aqueous-stirred macerate of lyophilized pomace.

In the case of the concentrations of the extracts ranging between 0.0625 and 0.25 , no ABTS-scavenging activity could be detected. Also, the lyophilized extract had the same behavior in aqueous media. 
The medium inhibition concentration in the case of $\mathrm{ABTS}^{\bullet+}$ scavenged radicals shows 10 times higher values than the one obtained in the case of DPPH ${ }^{\bullet}$ (Table 1) scavenged radicals, as shown in Table 3. Comparable values present the lyophilized samples and the refrigerated samples.

Table 3. IC $50^{1}$ values for $\mathrm{ABTS}^{\bullet+}$ scavenging activity.

\begin{tabular}{cc}
\hline Sample, $[\mathrm{mg} / \mathrm{mL}]$ & Ethanol-Water \\
\hline PRE & 0.23 \\
PDE & 1.76 \\
PLE & 0.29 \\
PLS & 1.06 \\
\hline
\end{tabular}

${ }^{1}$ IC 50: Half of the maxim inhibitory concentration.

As observed in Figures 6 and 7, the extract's superoxide radical-scavenged activity is presented in concentrations of 100 times lower compared with the previous determinations. The best results are obtained for the refrigerated extracts in alcoholic and aqueous media.

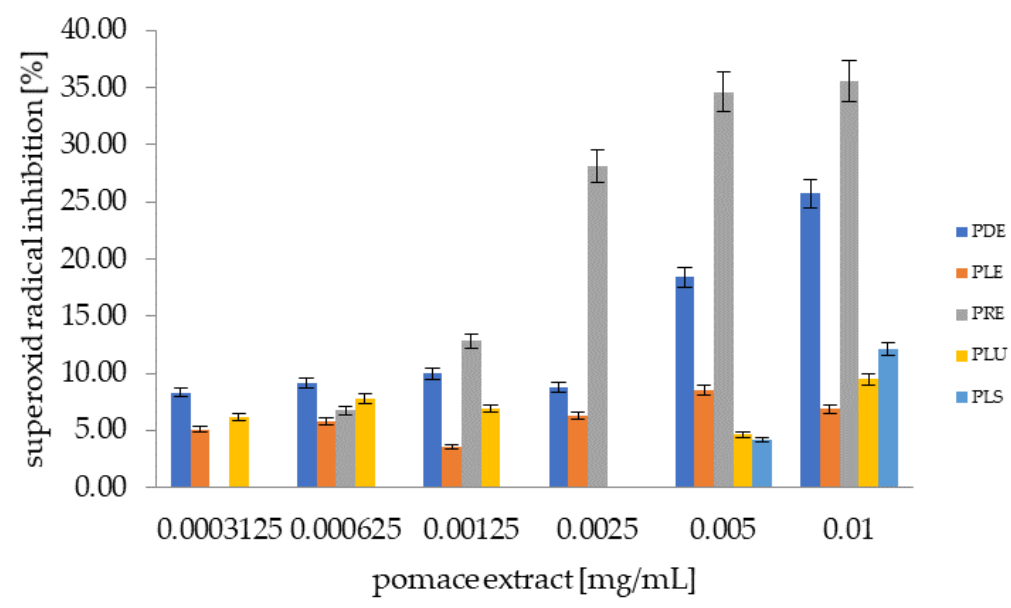

Figure 6. Superoxide radical \% scavenged at different marc concentrations in ethanol-water. PRE-hydroalcoholic extract of refrigerated pomace; PDE-hydroalcoholic extract of dry pomace; PLE-hydroalcoholic extract of lyophilized pomace; PLU-hydroalcoholic ultrasound macerate of lyophilized pomace; PLS-hydroalcoholic stirred macerate of lyophilized pomace.

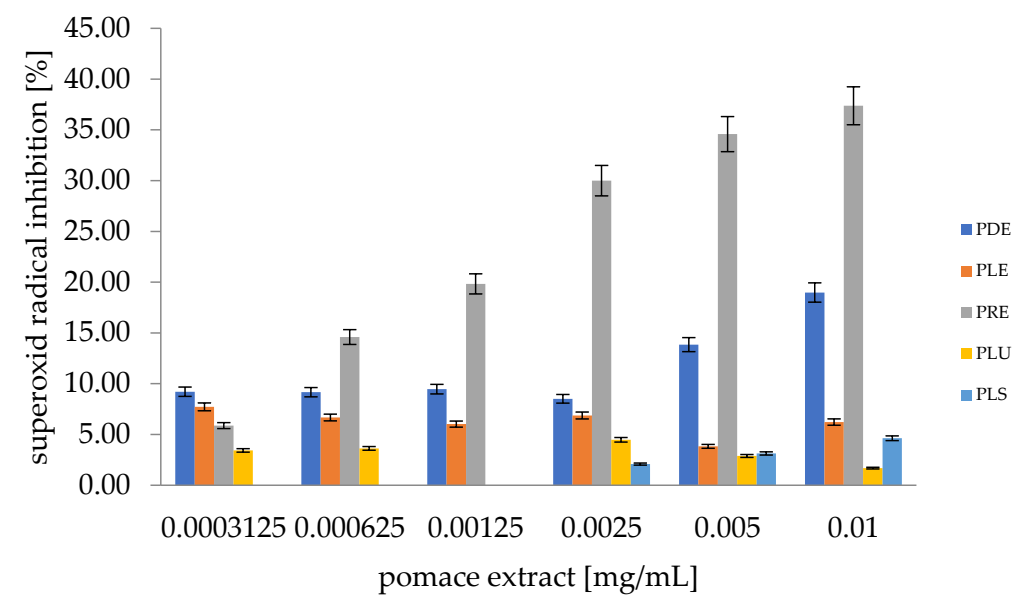

Figure 7. Superoxide radical-scavenged $\%$ at different marc concentrations in water. PRE-aqueous extract of refrigerated pomace; PDE-aqueous extract of dry pomace; PLE-aqueous extract of lyophilized pomace; PLU-aqueous ultrasound macerate of lyophilized pomace; PLS-aqueous-stirred macerate of lyophilized pomace. 
The IC 50 values determined for the NBT experiments had significant values for the extracts obtained in extractive conditions of the dried and refrigerated pomace samples (Table 4).

Table 4. IC $50^{1}$ values for superoxide radical-scavenging activity.

\begin{tabular}{ccc}
\hline Sample, $[\mathrm{mg} / \mathrm{mL}]$ & Ethanol-Water & Water \\
\hline PRE & 0.004 & 0.005 \\
PDE & 0.023 & 0.040 \\
\hline
\end{tabular}

${ }^{1}$ IC 50: Half of the maxim inhibitory concentration.

\subsection{Organophosphorus Compound Content}

The determination of the organophoshorus content is necessary to be considered, especially if the extracts are added to foodstuffs [53], as their toxicological characteristics play an important role. For this reason, an attempt was made to characterize them for the organophosphorus content, with respect to the favorable/limiting extraction conditions. Even though the determination method is not chromatography, which would involve separating the compounds from the extraction medium, the method used is modern and fast [54], characterized by a high degree of sensitivity, with the detection range between 0.05 and $-1.5 \mathrm{mM}$ substrate (chlorpyrifos-oxon). For this purpose, it was used in the electrochemical biosensor on which acetylcholinesterase was immobilized. The method was successfully used for such determinations in food products $[55,56]$.

The applied treatment influenced the residual amount of organophosphorus compound present in the analyzed samples (Table 5). The two variables may be the starting point in choosing the optimum conditions for polyhydroxyphenol extraction.

Table 5. Correlation between the percentage of inhibition and organophosphorus compounds concentration.

\begin{tabular}{ccc}
\hline Sample & Inhibition Percentage & $\begin{array}{c}\text { Pesticide Concentration } \\
\text { (Expressed in nmol } \\
\text { Chlorpyrifos-oxone Equivalent) }\end{array}$ \\
\hline PLS 2 & $16.70 \pm 0.71$ & $0.262 \pm 0.015$ \\
PLU 2 & $20.00 \pm 0.62$ & $0.583 \pm 0.032$ \\
PRS 2 & $21.43 \pm 0.92$ & $0.723 \pm 0.034$ \\
PRU 2 & $30.00 \pm 0.44$ & $1.564 \pm 0.043$ \\
PDU 2 & $7.40 \pm 0.43$ & $0.112 \pm 0.002$ \\
PDS 2 & $4.76 \pm 0.25$ & $0.074 \pm 0.001$ \\
PLS 1 & n.d. ${ }^{*}$ & n.d. \\
PLU 1 & n.d. & n.d. \\
PLE 1 & n.d. & n.d. \\
PLE 2 & n.d. & n.d. \\
PRE 2 & n.d. & n.d. \\
PDE 2 & n.d. & n.d. \\
\hline
\end{tabular}

${ }^{*}$ n.d.-not detected.

The pomace-conditioning parameters at $30^{\circ} \mathrm{C}$ determine the lowest pesticide content present in the final extract. The highest compound amount was detected in the extracts obtained from raw samples compared to the ultrasound-treated samples. Such behavior may be determined by the ultrasound treatment effect on the cell membrane. Their advanced disintegration increased the quantity of released substances.

\subsection{Wastewater Application Results}

The investigation aimed to determine the pomace extract's influence on hemp wastewater parameters. For nine days, the study developed the interval intended to determine the wastewater quality parameter change. The results obtained showed modifications of the wastewater parameters only during the first five days of monitoring. 
The $\mathrm{pH}$ values remain almost constant during the observation of approximately five units (figure not shown). Such results sustain the possibility of using the treated waters in further treatments as it will not influence the $\mathrm{pH}$ of the natural water bodies.

The pomace extract enhanced the turbidity of the sample after the first day (Figure 8). The formation of different assembling structures may determine the rising values observed for the samples treated at room temperature. We assume that the formation of the agglomerates might arise due to the presence of pectins in the wastewater and their precipitation after the addition of the hydroalcoholic extracts [57]. The advantage of such a mechanism creates the possibility of easier discharge for the formed colloids. In addition, the wastewaters could be considered for reuse after other processes for the water clarification.

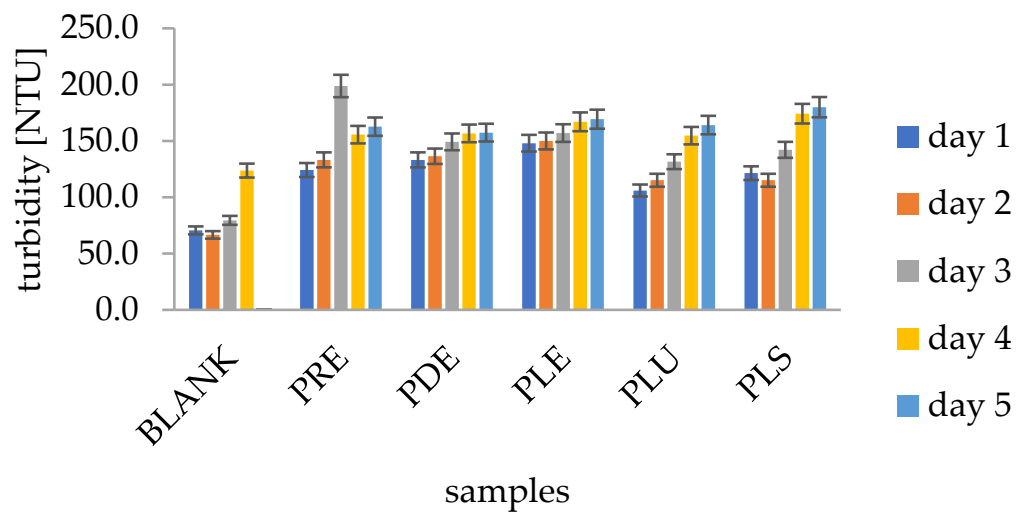

Figure 8. Turbidity evolution during the period analyzed. PRE-hydroalcoholic extract of refrigerated pomace; PDE-hydroalcoholic extract of dry pomace; PLE-hydroalcoholic extract of lyophilized pomace; PLU-hydroalcoholic ultrasound macerate of lyophilized pomace; PLS- hydroalcoholic stirred macerate of lyophilized pomace.

The general tendency for the dissolved oxygen quantity measured is to descend (Figure 9). It may be determined by the presence of the remanent yeast from the hemp wastewaters. A different behavior has the sample macerated with ultrasound. To fully understand the possible interactions, further additional investigations are necessary. For the moment, it can be considered that the activity of yeasts might be negatively affected by the ultrasound treatment.

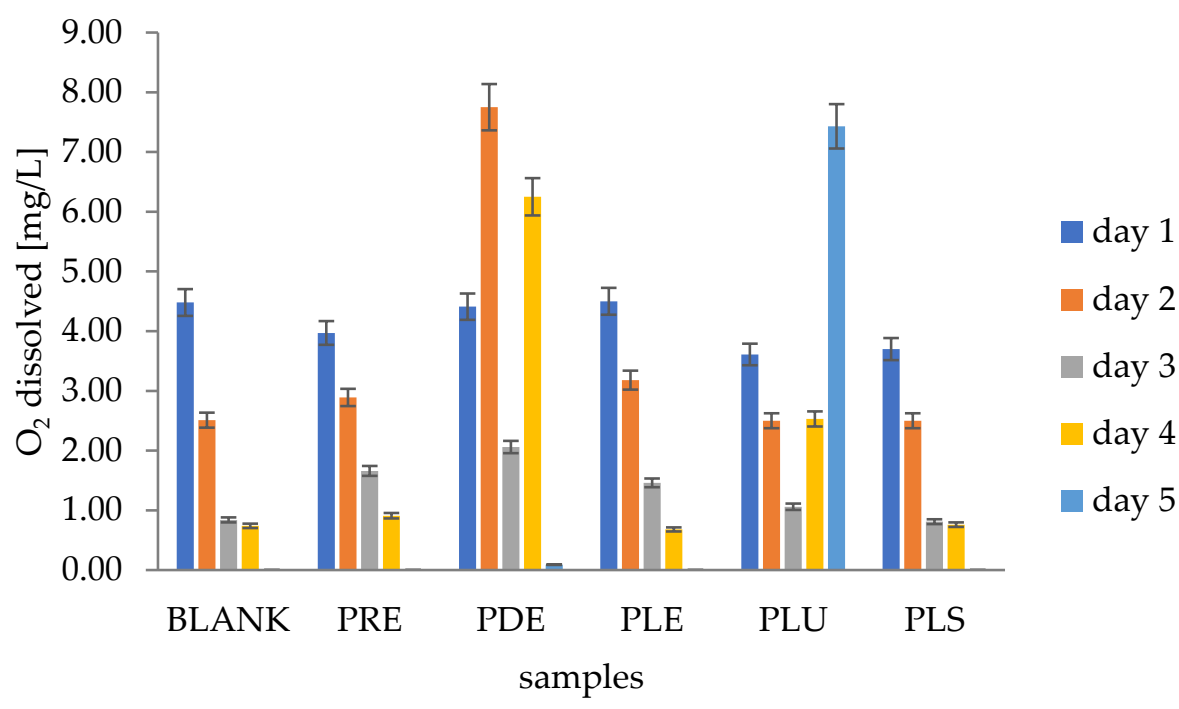

Figure 9. Dissolved oxygen evolution during the period analyzed. PRE-hydroalcoholic extract of refrigerated pomace; PDE-hydroalcoholic extract of dry pomace; PLE-hydroalcoholic extract of lyophilized pomace; PLU-hydroalcoholic ultrasound macerate of lyophilized pomace; PLShydroalcoholic stirred macerate of lyophilized pomace. 
Depending on the intended further use of the wastewaters, the results shown in Figure 10 offer a solid base for its reintegration. The registered values are lower compared with the ones for the untreated sample (blank).

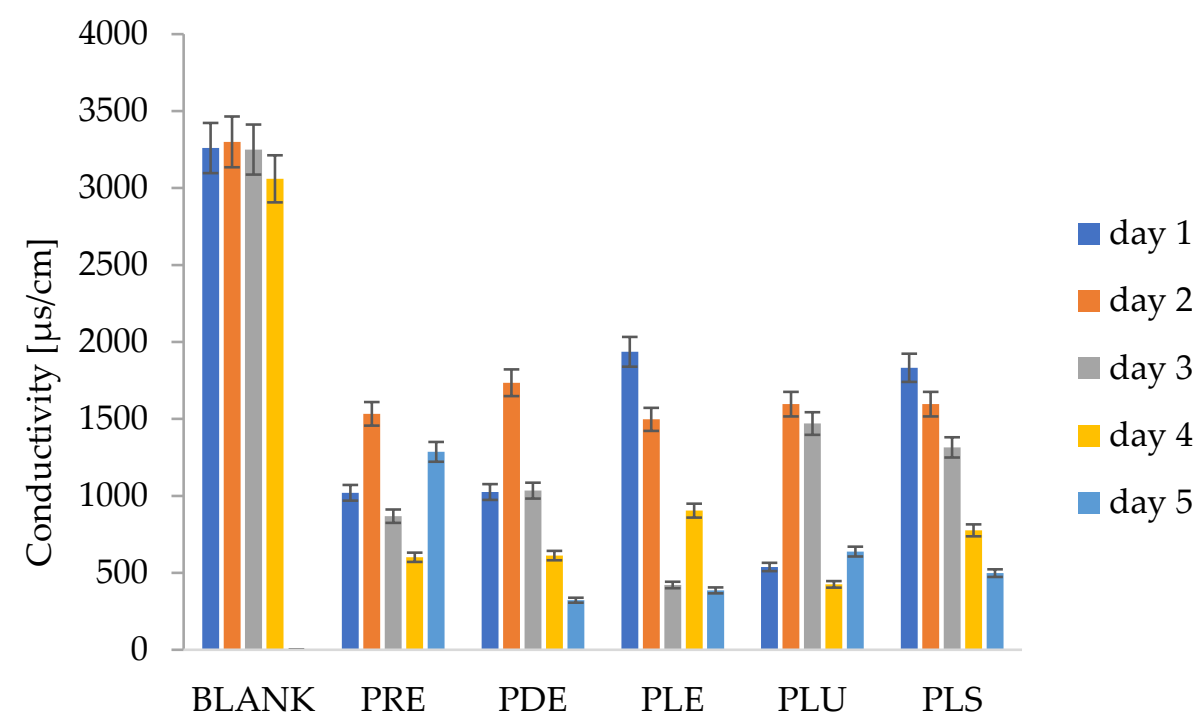

Figure 10. Conductivity evolution during the period analyzed. PRE-hydroalcoholic extract of refrigerated pomace; PDE-hydroalcoholic extract of dry pomace; PLE-hydroalcoholic extract of lyophilized pomace; PLU-hydroalcoholic ultrasound macerate of lyophilized pomace; PLS-hydroalcoholic stirred macerate of lyophilized pomace.

\section{Discussion}

Based on the presented results, it needs to be emphasized that the parameters used to extract the valuable compounds from pomace are influencing the total phenol content and antioxidant profile.

The values obtained for the TPC are in good agreement with the ones reported by other authors when levels between 30 and $70 \mathrm{mg} / \mathrm{g}$ were reported [58-61]. The high value obtained in the present study are for the lyophilized extract in ethanol/water.

The NBT method is used along with the classical ones. The enzymatic approach proved to be suitable for the determinations made, presenting a high sensibility.

Comparing the antioxidant activity obtained for the prepared samples, it can be observed that the presence of ethanol in the extraction process has a positive effect on the radical-scavenging activity, and the results obtained in the present paper are in good correlation with the previously reported values for the grape pomace.

Our results show that the lyophilization process could be considered a method for valuable active compound preservation, as was previously shown by Chikwanha et al., who obtained values for the TPC that range from 106 to $206 \mathrm{~g} / \mathrm{kg}$ [62]. Additionally, the ultrasound-assisted method in aqueous media proved to be an excellent perspective for the extraction yield, even if the procedure proved that the yield can be attributed to the non-optimized ultrasonic treatment time. It could be viewed as a sustainable alternative to the classical approaches since it contributes to the decrease of the reaction time and uses an eco-friendly solvent [63]. These findings open the possibility for the optimization of the pretreatment conditions.

The alcoholic extraction media seems to represent a suitable environment for active compound extraction. Depending on the application field, the aqueous alternative could also be considered. For the latter, parameter optimization must be regarded to increase efficiency while maintaining the ecological attribute.

The drying conditions used were not very aggressive compared with the one presented in the literature $\left(60-85^{\circ} \mathrm{C}\right)$ [63], a case in which the increase in polyhydroxyphenols is significant compared to the native samples. Some extracts did not present antioxidant 
and antiradical activity, as observed from the data presented, because of the pretreatments applied to the byproducts, which involved different physical regimes.

We found that the \% of antiradical scavenging activity showed the highest values for the dried and refrigerated extracts comparable to the values reported in the literature, with values between 61 and 72 for the oven-dried samples and between 71 and 82 for the freeze-dried samples [62].

The main standardized parameters were analyzed regarding the application of the obtained extracts. Their evolution during the surveillance interval offered solid preliminary information about the benefits of such extracts for wastewater improvement. Further investigations are needed to clarify the exact chemical and biochemical mechanism involved and the possibility to be used for other wastewater treatment.

These results are also supported by the literature [61,64].

In general, the pomace has a high degree of heterogeneity. Such a characteristic is a limitation of the research, as each type of product is necessary for the individual characterizations. The pedologic specificity and the grape variety give particular features to each of the resulting pomace profiles [62].

The results obtained from the determination of the total phenolic content and the antiradical activity of the analyzed samples showed that they could be successfully used for different applications. We believe that our results open perspectives for finding new green methods suitable for the extraction of valuable compounds from pomace.

\section{Conclusions}

In conclusion, the grape pomace can be used for obtaining different extracts under different extraction conditions. The total phenol content was shown to be higher when extraction was performed in a mixture of ethanol and water, while lyophilization also plays an important role in obtaining high values. The evaluation of the antioxidant properties of the obtained extracts indicated that the extracts can be successfully used for the remediation of wastewater, as we have shown in these preliminary studies.

The relationship between the total phenolic content and the antioxidant and antiradical activity in the lyophilized extract should be further evaluated in future studies, as the high content of phenolic compounds could be better valorized for other applications.

Author Contributions: Conceptualization, F.-D.M. and S.G.; methodology, F.-D.M. and S.G.; formal analysis, I.C.; investigation, S.G.; resources, M.R., S.C. and C.-S.U.; writing-original draft preparation, S.G.; writing - review and editing, F.-D.M.; funding acquisition, F.-D.M. All authors have read and agreed to the published version of the manuscript.

Funding: F.-D.M., S.G. and S.C. gratefully acknowledge financial support from Hubert-Curien Brâncuși “FOODVALUE" Project, PN-III-P3-3.1-PM-RO-FR-2016, Ctr No 86BM/2017, Valorisation of winery by-products-application for wastewater treatment, "FOODVALUE".

Institutional Review Board Statement: Not applicable.

Informed Consent Statement: Not applicable.

Data Availability Statement: The data presented in this study are available on request from the corresponding author.

Acknowledgments: The authors thank the research team from the Biosensors Analysis Environment Laboratory of the Université de Perpignan Via Domitia, Perpignan, France (Gaëlle Catanante, JeanLouis Marty and Georges Istamboulie) for all the logistics support provided.

Conflicts of Interest: The authors declare no conflict of interest. 


\section{References}

1. Amran, M.A.; Palaniveloo, K.; Fauzi, R.; Satar, N.M.; Mohidin, T.B.M.; Mohan, G.; Razak, S.A.; Arunasalam, M.; Nagappan, T.; Seelan, J.S.S. Value-Added Metabolites from Agricultural Waste and Application of Green Extraction Techniques. Sustainability 2021, 13, 11432. [CrossRef]

2. Donner, M.; Gohier, R.; de Vries, H. A new circular business model typology for creating value from agro-waste. Sci. Total Environ. 2020, 716, 137065. [CrossRef] [PubMed]

3. Donner, M.; Verniquet, A.; Broeze, J.; Kayser, K.; De Vries, H. Critical success and risk factors for circular business models valorising agricultural waste and by-products. Resour. Conserv. Recycl. 2020, 165, 105236. [CrossRef]

4. Duque-Acevedo, M.; Belmonte-Ureña, L.J.; Yakovleva, N.; Camacho-Ferre, F. Analysis of the Circular Economic Production Models and Their Approach in Agriculture and Agricultural Waste Biomass Management. Int. J. Environ. Res. Public Health 2020, 17, 9549. [CrossRef] [PubMed]

5. Kapoor, R.; Ghosh, P.; Kumar, M.; Sengupta, S.; Gupta, A.; Kumar, S.; Vijay, V.; Kumar, V.; Vijay, V.K.; Pant, D. Valorization of agricultural waste for biogas based circular economy in India: A research outlook. Bioresour. Technol. 2020, 304, 123036. [CrossRef] [PubMed]

6. Puglia, D.; Pezzolla, D.; Gigliotti, G.; Torre, L.; Bartucca, M.; Del Buono, D. The Opportunity of Valorizing Agricultural Waste, Through Its Conversion into Biostimulants, Biofertilizers, and Biopolymers. Sustainability 2021, 13, 2710. [CrossRef]

7. Toop, T.A.; Ward, S.; Oldfield, T.; Hull, M.; Kirby, M.E.; Theodorou, M.K. AgroCycle-developing a circular economy in agriculture. In Proceedings of the 1st International Conference on Sustainable Energy and Resource Use in Food Chains (ICFES)/Symposium on Heat Recovery and Efficient Conversion and Utilisation of Waste Heat, Windsor, UK, 19-20 April 2017; Elsevier Science BV: Windsor, UK, 2017; pp. 76-80.

8. Yaashikaa, P.; Kumar, P.S.; Varjani, S. Valorization of agro-industrial wastes for biorefinery process and circular bioeconomy: A critical review. Bioresour. Technol. 2021, 343, 126126. [CrossRef]

9. Chowdhary, P.; Gupta, A.; Gnansounou, E.; Pandey, A.; Chaturvedi, P. Current trends and possibilities for exploitation of Grape pomace as a potential source for value addition. Environ. Pollut. 2021, 278, 116796. [CrossRef]

10. Kabir, M.M.; Akter, M.M.; Khandaker, S.; Gilroyed, B.H.; Alam, D.U.; Hakim, M.; Awual, R. Highly effective agro-waste based functional green adsorbents for toxic chromium(VI) ion removal from wastewater. J. Mol. Liq. 2021, 347, 118327. [CrossRef]

11. Narasaiah, B.P.; Mandal, B.K. Remediation of azo-dyes based toxicity by agro-waste cotton boll peels mediated palladium nanoparticles. J. Saudi Chem. Soc. 2019, 24, 267-281. [CrossRef]

12. Khan, A.H.; Khan, N.A.; Zubair, M.; Shaida, M.A.; Manzar, M.S.; Abutaleb, A.; Naushad, M.; Iqbal, J. Sustainable green nanoadsorbents for remediation of pharmaceuticals from water and wastewater: A critical review. Environ. Res. 2021, $204,112243$. [CrossRef]

13. Khalith, S.M.; Ramalingam, R.; Karuppannan, S.K.; Dowlath, M.J.H.; Kumar, R.; Vijayalakshmi, S.; Maheshwari, R.U.; Arunachalam, K.D. Synthesis and characterization of polyphenols functionalized graphitic hematite nanocomposite adsorbent from an agro waste and its application for removal of Cs from aqueous solution. Chemosphere 2021, 286, 131493. [CrossRef]

14. Othmani, A.; Magdouli, S.; Kumar, P.S.; Kapoor, A.; Chellam, P.V.; Gökkuş, Ö. Agricultural waste materials for adsorptive removal of phenols, chromium (VI) and cadmium (II) from wastewater: A review. Environ. Res. 2021, 204, 111916. [CrossRef] [PubMed]

15. Giordano, E.D.; Bosio, B.; Camiscia, P.; Picó, G.A.; Valetti, N.W. Cellulose and its cationic derivative obtained from soybean hull as a tool for the remediation of textile dyes in wastewater: Physicochemical characterization and molecular mechanism interaction. Biocatal. Agric. Biotechnol. 2021, 36, 102139. [CrossRef]

16. Llobera, A.; Cañellas, J. Dietary fibre content and antioxidant activity of Manto Negro red grape (Vitis vinifera): Pomace and stem. Food Chem. 2007, 101, 659-666. [CrossRef]

17. Beres, C.; Costa, G.N.S.; Cabezudo, I.; da Silva-James, N.K.; Teles, A.S.C.; Cruz, A.P.; Mellinger-Silva, C.; Tonon, R.V.; Cabral, L.M.C.; Freitas, S.P. Towards integral utilization of grape pomace from winemaking process: A review. Waste Manag. 2017, 68, 581-594. [CrossRef]

18. Luo, L.; Cui, Y.; Zhang, S.; Li, L.; Suo, H.; Sun, B. Detailed phenolic composition of Vidal grape pomace by ultrahigh-performance liquid chromatography-tandem mass spectrometry. J. Chromatogr. B 2017, 1068-1069, 201-209. [CrossRef]

19. Zhu, F.; Du, B.; Zheng, L.; Li, J. Advance on the bioactivity and potential applications of dietary fibre from grape pomace. Food Chem. 2015, 186, 207-212. [CrossRef]

20. Deng, Q.; Penner, M.H.; Zhao, Y. Chemical composition of dietary fiber and polyphenols of five different varieties of wine grape pomace skins. Food Res. Int. 2011, 44, 2712-2720. [CrossRef]

21. Zhao, J.X.; Li, Q.; Zhang, R.X.; Liu, W.Z.; Ren, Y.S.; Zhang, C.X.; Zhang, J.X. Effect of dietary grape pomace on growth performance, meat quality and antioxidant activity in ram lambs. Anim. Feed Sci. Technol. 2018, 236, 76-85. [CrossRef]

22. Li, W.; Yao, R.; Xie, L.; Liu, J.; Weng, X.; Yue, X.; Li, F. Dietary supplementation of grape seed tannin extract stimulated testis development, changed fatty acid profiles and increased testis antioxidant capacity in pre-puberty hu lambs. Theriogenology 2021, 172, 160-168. [CrossRef] [PubMed]

23. Bai, C.; Dallasega, P.; Orzes, G.; Sarkis, J. Industry 4.0 technologies assessment: A sustainability perspective. Int. J. Prod. Econ. 2020, 229, 107776. [CrossRef] 
24. Solari-Godiño, F.A.; Pérez-Jiménez, J.; Saura-Calixto, F.; Borderías, A.; Moreno, H. Anchovy mince (Engraulis ringens) enriched with polyphenol-rich grape pomace dietary fibre: In vitro polyphenols bioaccessibility, antioxidant and physico-chemical properties. Food Res. Int. 2017, 102, 639-646. [CrossRef] [PubMed]

25. Kandylis, P.; Dimitrellou, D.; Moschakis, T. Recent applications of grapes and their derivatives in dairy products. Trends Food Sci. Technol. 2021, 114, 696-711. [CrossRef]

26. Jara-Palacios, M.J.; Hernanz, D.; Escudero-Gilete, M.L.; Heredia, F.J. The Use of Grape Seed Byproducts Rich in Flavonoids to Improve the Antioxidant Potential of Red Wines. Molecules 2016, 21, 1526. [CrossRef] [PubMed]

27. Bertol, T.M.; Ludke, J.V.; De Campos, R.M.L.; Kawski, V.L.; Junior, A.C.; De Figueiredo, E.A.P. Inclusion of grape pomace in the diet of pigs on pork quality and oxidative stability of omega-3 enriched fat. Ciênc. Rural 2017, 47. [CrossRef]

28. Mu, C.; Yang, W.; Wang, P.; Zhao, J.; Hao, X.; Zhang, J. Effects of high-concentrate diet supplemented with grape seed proanthocyanidins on growth performance, liver function, meat quality, and antioxidant activity in finishing lambs. Anim. Feed Sci. Technol. 2020, 266, 114518. [CrossRef]

29. Sagdic, O.; Ozturk, I.; Ozkan, G.; Yetim, H.; Ekici, L.; Yilmaz, M.T. RP-HPLC-DAD analysis of phenolic compounds in pomace extracts from five grape cultivars: Evaluation of their antioxidant, antiradical and antifungal activities in orange and apple juices. Food Chem. 2011, 126, 1749-1758. [CrossRef] [PubMed]

30. Brenes, A.; Viveros, A.; Chamorro, S.; Arija, I. Use of polyphenol-rich grape by-products in monogastric nutrition. A review. Anim. Feed Sci. Technol. 2015, 211, 1-17. [CrossRef]

31. Manconi, M.; Marongiu, F.; Castangia, I.; Manca, M.L.; Caddeo, C.; Tuberoso, C.I.G.; Hallewin, G.D.; Bacchetta, G.; Fadda, A.M. Polymer-associated liposomes for the oral delivery of grape pomace extract. Colloids Surf. B Biointerfaces 2016, 146, 910-917. [CrossRef]

32. Denny, C.; Lazarini, J.; Franchin, M.; Melo, P.; Pereira, G.; Massarioli, A.; Moreno, I.; Paschoal, J.; de Alencar, S.M.; Rosalen, P. Bioprospection of Petit Verdot grape pomace as a source of anti-inflammatory compounds. J. Funct. Foods 2014, 8, 292-300. [CrossRef]

33. Gonçalves, G.A.; Soares, A.A.; Corrêa, R.C.G.; Barros, L.; Haminiuk, C.; Peralta, R.M.; Ferreira, I.C.; Bracht, A. Merlot grape pomace hydroalcoholic extract improves the oxidative and inflammatory states of rats with adjuvant-induced arthritis. J. Funct. Foods 2017, 33, 408-418. [CrossRef]

34. Albuquerque, J.G.F.; Assis, V.L.; Almeida, A.J.P.O; Basílio, I.J.L.D.; Luciano, M.N.; Meireles, B.R.L.A.; Cordeiro, M.T.M.; Araújo, I.G.A.; Veras, R.; Ribeiro, T.P.; et al. Antioxidant and vasorelaxant activities induced by northeastern Brazilian fermented grape skins. BMC Complement. Altern. Med. 2017, 17, 376. [CrossRef]

35. De Oliveira, A.P.; Módenes, A.N.; Bragião, M.E.; Hinterholz, C.L.; Trigueros, D.E.; Bezerra, I.G.D.O. Use of grape pomace as a biosorbent for the removal of the Brown KROM KGT dye. Bioresour. Technol. Rep. 2018, 2, 92-99. [CrossRef]

36. Papadaki, E.; Mantzouridou, F. Citric acid production from the integration of Spanish-style green olive processing wastewaters with white grape pomace by Aspergillus niger. Bioresour. Technol. 2019, 280, 59-69. [CrossRef]

37. Meini, M.-R.; Cabezudo, I.; Galetto, C.S.; Romanini, D. Production of grape pomace extracts with enhanced antioxidant and prebiotic activities through solid-state fermentation by Aspergillus niger and Aspergillus oryzae. Food Biosci. 2021, $42,101168$. [CrossRef]

38. Panić, M.; Gunjević, V.; Radošević, K.; Bubalo, M.C.; Ganić, K.; Redovniković, I. COSMOtherm as an Effective Tool for Selection of Deep Eutectic Solvents Based Ready-To-Use Extracts from Graševina Grape Pomace. Molecules 2021, 26, 4722. [CrossRef] [PubMed]

39. Erinle, T.J.; Oladokun, S.; MacIsaac, J.; Rathgeber, B.; Adewole, D. Dietary grape pomace-Effects on growth performance, intestinal health, blood parameters, and breast muscle myopathies of broiler chickens. Poult. Sci. 2021, 101, 101519. [CrossRef] [PubMed]

40. Diaz-Ramirez, J.; Urbina, L.; Eceiza, A.; Retegi, A.; Gabilondo, N. Superabsorbent bacterial cellulose spheres biosynthesized from winery by-products as natural carriers for fertilizers. Int. J. Biol. Macromol. 2021, 191, 1212-1220. [CrossRef]

41. Díaz, A.B.; Bolívar, J.; de Ory, I.; Caro, I.; Blandino, A. Applicability of enzymatic extracts obtained by solid state fermentation on grape pomace and orange peels mixtures in must clarification. LWT 2011, 44, 840-846. [CrossRef]

42. El Achkar, J.H.; Lendormi, T.; Hobaika, Z.; Salameh, D.; Louka, N.; Maroun, R.G.; Lanoisellé, J.-L. Anaerobic digestion of nine varieties of grape pomace: Correlation between biochemical composition and methane production. Biomass-Bioenergy 2017, 107, 335-344. [CrossRef]

43. Nayak, A.; Bhushan, B.; Gupta, V.; Rodriguez-Turienzo, L. Development of a green and sustainable clean up system from grape pomace for heavy metal remediation. J. Environ. Chem. Eng. 2016, 4, 4342-4353. [CrossRef]

44. Zietsman, A.J.; Moore, J.P.; Fangel, J.U.; Willats, W.G.; Vivier, M.A. Combining hydrothermal pretreatment with enzymes de-pectinates and exposes the innermost xyloglucan-rich hemicellulose layers of wine grape pomace. Food Chem. 2017, 232, 340-350. [CrossRef]

45. Pintać, D.; Majkić, T.; Torovic, L.; Orčić, D.; Beara, I.; Simin, N.; Mimica-Dukić, N.; Lesjak, M. Solvent selection for efficient extraction of bioactive compounds from grape pomace. Ind. Crop. Prod. 2018, 111, 379-390. [CrossRef]

46. El Achkar, J.H.; Lendormi, T.; Salameh, D.; Louka, N.; Maroun, R.G.; Lanoisellé, J.-L.; Hobaika, Z. Influence of pretreatment conditions on lignocellulosic fractions and methane production from grape pomace. Bioresour. Technol. 2018, 247, 881-889. [CrossRef] 
47. Raota, C.S.; Cerbaro, A.F.; Salvador, M.; Delamare, A.P.L.; Echeverrigaray, S.; Crespo, J.D.S.; da Silva, T.B.; Giovanela, M. Green synthesis of silver nanoparticles using an extract of Ives cultivar (Vitis labrusca) pomace: Characterization and application in wastewater disinfection. J. Environ. Chem. Eng. 2019, 7, 103383. [CrossRef]

48. Becker, M.; Nunes, G.; Ribeiro, D.; Silva, F.; Catanante, G.; Marty, J. Determination of the Antioxidant Capacity of Red Fruits by Miniaturized Spectrophotometry Assays. J. Braz. Chem. Soc. 2019. [CrossRef]

49. Becker, M.M.; Gaëlle Catanantea, G.; Mármol, I.; Rodríguez Yoldi, M.J.; Mishrad, R.K.; Barbosa, S.; Núñez Burcio, O.; Silva Nunes, G.; Marty, J.-L. Phenolic Composition, Antioxidant Capacity and Antiproliferative Activity of Ten Exotic Amazonian fruit. SDRP J. Food Sci. Tehnol. 2020, 5, 49-65.

50. Andreescu, S.; Barthelmebs, L.; Marty, J.-L. Immobilization of acetylcholinesterase on screen-printed electrodes: Comparative study between three immobilization methods and applications to the detection of organophosphorus insecticides. Anal. Chim. Acta 2002, 464, 171-180. [CrossRef]

51. López-Miranda, S.; Serrano-Martínez, A.; Hernández-Sánchez, P.; Guardiola, L.; Pérez-Sánchez, H.; Fortea, I.; Gabaldón, J.A.; Núñez-Delicado, E. Use of cyclodextrins to recover catechin and epicatechin from red grape pomace. Food Chem. 2016, 203, 379-385. [CrossRef]

52. De Torres, C.; Schumacher, R.; Alañón, M.; Pérez-Coello, M.; Díaz-Maroto, M. Freeze-dried grape skins by-products to enhance the quality of white wines from neutral grape varieties. Food Res. Int. 2015, 69, 97-105. [CrossRef]

53. De Azevedo, P.O.D.S.; Aliakbarian, B.; Casazza, A.A.; LeBlanc, J.G.; Perego, P.; Souza Oliveira, R.P.D. Production of fermented skim milk supplemented with different grape pomace extracts: Effect on viability and acidification performance of probiotic cultures. PharmaNutrition 2018, 6, 64-68. [CrossRef]

54. Samsidar, A.; Siddiquee, S.; Shaarani, S.M. A review of extraction, analytical and advanced methods for determination of pesticides in environment and foodstuffs. Trends Food Sci. Technol. 2018, 71, 188-201. [CrossRef]

55. El-Moghazy, A.; Soliman, E.; Ibrahim, H.; Noguer, T.; Marty, J.-L.; Istamboulie, G. Ultra-sensitive biosensor based on genetically engineered acetylcholinesterase immobilized in poly (vinyl alcohol)/Fe-Ni alloy nanocomposite for phosmet detection in olive oil. Food Chem. 2016, 203, 73-78. [CrossRef] [PubMed]

56. Aftim, N.; Istamboulié, G.; Piletska, E.; Piletsky, S.; Calas-Blanchard, C.; Noguer, T. Biosensor-assisted selection of optimal parameters for designing molecularly imprinted polymers selective to phosmet insecticide. Talanta 2017, 174, 414-419. [CrossRef]

57. Guo, X.; Zhang, T.; Meng, H.; Yu, S. Ethanol precipitation of sugar beet pectins as affected by electrostatic interactions between counter ions and pectin chains. Food Hydrocoll. 2017, 65, 187-197. [CrossRef]

58. Rockenbach, I.I.; Rodrigues, E.; Gonzaga, L.V.; Caliari, V.; Genovese, M.I.; de Souza Schmidt Gonçalves, A.E.; Fett, R. Phenolic compounds content and antioxidant activity in pomace from selected red grapes (Vitis vinifera L. and Vitis labrusca L.) widely produced in Brazil. Food Chem. 2011, 127, 174-179. [CrossRef]

59. Marinelli, V.; Padalino, L.; Nardiello, D.; Del Nobile, M.A.; Conte, A. New Approach to Enrich Pasta with Polyphenols from Grape Marc. J. Chem. 2015, 2015, 1-8. [CrossRef]

60. Negro, C.; Aprile, A.; Luvisi, A.; De Bellis, L.; Miceli, A. Antioxidant Activity and Polyphenols Characterization of Four Monovarietal Grape Pomaces from Salento (Apulia, Italy). Antioxidants 2021, 10, 1406. [CrossRef]

61. Nayak, A.; Bhushan, B.; Rosales, A.; Turienzo, L.R.; Cortina, J.L. Valorisation potential of Cabernet grape pomace for the recovery of polyphenols: Process intensification, optimisation and study of kinetics. Food Bioprod. Process. 2018, 109, 74-85. [CrossRef]

62. Chikwanha, O.C.; Raffrenato, E.; Opara, U.L.; Fawole, O.A.; Setati, M.E.; Muchenje, V.; Mapiye, C. Impact of dehydration on retention of bioactive profile and biological activities of different grape (Vitis vinifera L.) pomace varieties. Anim. Feed Sci. Technol. 2018, 244, 116-127. [CrossRef]

63. Goula, A.; Thymiatis, K.; Kaderides, K. Valorization of grape pomace: Drying behavior and ultrasound extraction of phenolics. Food Bioprod. Process. 2016, 100, 132-144. [CrossRef]

64. Gouvinhas, I.; Santos, R.A.; Queiroz, M.; Leal, C.; Saavedra, M.J.; Domínguez-Perles, R.; Rodrigues, M.; Barros, A. Monitoring the antioxidant and antimicrobial power of grape (Vitis vinifera L.) stems phenolics over long-term storage. Ind. Crop. Prod. 2018, 126, 83-91. [CrossRef] 